\title{
TRANSIÇÕES NA IMAGEM DO BRASIL EM PORTUGAL VEICULADA PELA IMPRENSA: UM ESTUDO SOBRE AS MATÉRIAS PUBLICADAS NAS REVISTAS ILUSTRADAS PORTUGUESAS (1834- 1922)
}

\author{
Ana Suely Pinho Lopes ${ }^{1}$ \\ Universidade Fernando Pessoa (UFP - Porto/Portugal) \\ Jorge Pedro Sousa ${ }^{2}$ \\ Universidade Fernando Pessoa (UFP - Porto/Portugal)
}

\begin{abstract}
Resumo
O objetivo deste texto é analisar a transição na imagem do Brasil veiculada pela imprensa fundamentada no estudo das matérias produzidas pelas revistas ilustradas portuguesas (1834-1922). Para realizar a análise são separados os títulos das matérias que dizem respeito ao Brasil, que enfatizam os temas relevantes para o estudo no âmbito da história do Brasil do período referente e categorizados de acordo com a intensidade e a frequência com que surgem nas matérias. Como referencial teórico utiliza-se a linha de comunicação, imagem, identidade cultural e o estudo da narrativa jornalística. Situa-se como um estudo exploratório descritivo. Diante das matérias analisadas acreditase, atingir o objetivo desejado uma vez que o estudo permite identificar os pontos relevantes que chamam a atenção sobre o Brasil naquela época e a importância que foi dada a cada um deles, considerando o nível de relevância por tema abordado a considerar a avaliação por décadas no período abordado.
\end{abstract}

Palavras-chave: Comunicação. Identidade cultural. Imagem Brasil

\section{SHIFTS OF THE BRAZILIAN IMAGE IN PORTUGAL IN PRESS CIRCULATED CONTENT: A STUDY OF THE PUBLISHED MATERIAL IN ILLUSTRATED PORTUGUESE MAGAZINES (1834-1922)}

\begin{abstract}
This text examines the shift of Brazil's national image through an analysis of illustrated Portuguese magazine content circulated by the press (1834-1922). The analysis that follows is separated into different chapters based on the recurrent themes in the primary source material, as well as the relevance of these themes to interpreting the image of Brazil during the historical period in question. Additionally, the chapters are categorized in a way that considers the frequency and intensity of such themes that arise in the magazines. Various theoretical analyses are employed in this exploratory descriptive study including: line of communication, image, cultural identity, and narrative journalistic. Given the analyzed materials, the study was successful in that it permitted the identification of important historical considerations about Brazil during its first century of independence, and the importance that was assigned to each consideration given its relevance in each respective decade.
\end{abstract}

Keywords: Communication. Cultural Identity. Brazilian image.

\footnotetext{
${ }^{1}$ Doutoranda em Ciência da Informação - Comunicação e estudos midiáticos na Universidade Fernando Pessoa. 2 Professor catedrático da Universidade Fernando Pessoa (UFP - Porto/Portugal).
}

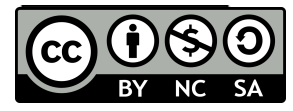




\section{INTRODUÇÃO}

Estudar o discurso da mídia implica encarar os meios de comunicação em sociedade como uma instância de mediação de significados (SILVESRSTONE, 2002, p. 43). As imagens midiáticas podem ser consideradas, nesse contexto, representações discursivas complexas atribuidoras de significado a realidades singulares, podendo indiciar não apenas elementos concretos destas realidades mas também os valores, interesses e objetivos dos enunciadores, operando por analogia entre representação e objeto representado (JOLY, 1996; SILVERSTONE, 2002; BALDISERA, 2003). Baldissera (2003) sugere, igualmente, que uma imagem resulta das impressões manifestas discursivamente em relação a algo, podendo ser positiva, quando promove empatia e/ou simpatia em relação à realidade representada, ou negativa, quando promove aversão ou antipatia, tendo, portanto, sempre um carácter apreciativo, valorativo e de construção mental. Além disso, a construção de uma imagem, dentro de um contexto sociocultural a partir do qual se produz significação para o mundo, depende dos discursos pré-existentes que circulam no meio social e de conhecimentos prévios, bem como de informações e experiências novas (BALDISERA, 2003). Portanto, as imagens dos países na sua própria mídia e na mídia de países terceiros será um filão de pesquisa, pois uma cultura nacional é, essencialmente, um discurso simbólico identitário que se delimita por contraposição a outros discursos identitários de outras culturas nacionais, razão pela qual cada cultura nacional se construirá em função das diferenças que estabelece com outras culturas nacionais, estabelecidas, também elas, por meio dos discursos que, disponíveis socialmente, promovem a circulação universal de signos e padrões de significado, compreensíveis e interpretados de acordo com contextos culturais determinados (HALL, 2002, p. 78).

\section{A DEFINIÇÃO DO TERMO IMAGEM}

Como se definiria uma imagem? Esta pergunta não é usual no imaginário coletivo, tendo em vista que as pessoas, na maioria das vezes, interpretam como uma imagem apenas aquilo que se passa na TV e que veem nas fotografias. No entanto, olhando por outro viés, no caso, ao examinar pesquisas científicas no contexto da teoria da imagem, encontramos diversas traduções para este termo conforme a área da pesquisa.

No entendimento de Joly (1996), para compreendermos o que é a imagem, podemos partir do sentido de que esta "seria um objeto segundo com relação a um outro que ela representaria de acordo com certas leis particulares" (JOLY, 1996, p.14). Quer dizer, a função 
de representação é a principal que uma imagem adquire no seu momento de existência. Sendo assim, esta tem diversas utilidades seja para representar um estado de espírito ou até mesmo uma organização.

Nessa perspectiva, podemos nos deparar com vários estudos mais detalhados sobre a imagem e suas características. Dondis (2007) defende uma abordagem da percepção visual denominada "alfabetismo visual", seria o caminho para a leitura e compreensão das imagens. Este princípio afirma que os indivíduos deveriam ser instruídos a uma percepção natural de sentidos de maneira que por meio da aprendizagem das premissas essenciais da linguagem visual os receptores extraiam os mesmos sentidos.

Ainda no contexto da tecnologia da informação tão presente em nossos afazeres diários, para a arquivologia que faz muito uso da técnica da digitalização de documentos Imagem $^{3}$ significa "Representação gráfica, plástica ou fotográfica de seres, objetos ou fatos".

A digitalização significa "Representação gráfica, plástica ou fotográfica de seres, objetos ou fatos". A digitalização de documentos é vista como "uma inovação cada vez mais comum nas organizações públicas brasileiras, fato decorrente da necessidade da agilidade na recuperação e utilização da informação" (SCHAFER; FLORES, 2014).

Os profissionais de comunicação lidam com uma sociedade na qual a cultura e a informação possuem um cuidado predominantemente visual. Onde o "visual predomina, o verbal tem "a função de acréscimo" (DONDIS, 2007, p. 12). Por isto, as relações públicas lidam com imagens em vários âmbitos de seu trabalho, para construir a imagem de uma empresa, de uma marca, de uma pessoa, de uma organização de terceiro setor, entre outros.

Dado ao seu aspecto universal, a linguagem visual, permite aos profissionais de relações públicas que lidam com o equilíbrio entre a identidade e a imagem das organizações, e até mesmo de pessoas perante os seus públicos, a assim difundir sentidos, ideias e conceitos através mesmo de pessoas perante os seus públicos, a assim difundir sentidos, ideias e conceitos através das imagens.

O uso da imagem como ferramenta da comunicação se faz essencial na sociedade contemporânea. Por isto, atualmente percebemos que as imagens são capazes de disseminar mais sentidos e entendimentos que outras formas de representação. Ela permite que sua compreensão seja obtida por quase todos, percorre o mundo com mais rapidez através das mídias digitais e amplia espaço para com que todos encontrem seu sentido, sua mensagem

\footnotetext{
${ }^{3}$ Imagem - Dicionário Brasileiro de terminologia arquivística. Disponível em: http://www.arquivonacio nal.gov.br/images/pdf/Dicion_Term_Arquiv.pdf
} 
visual. Sendo assim, pode-se perceber que a utilização de imagens pela comunicação para disseminar conteúdo é necessária para a sua melhor compreensão ou até mesmo pode ser a única utilizada, dispensando o uso de elementos textuais.

\section{IDENTIDADE CULTURAL}

Discorrer sobre o sentido de identidade apresenta-se desafiador, uma vez que são múltiplas e interdisciplinares as perspectivas que se lançam sobre essa ideia. Desse ponto o risco e a dificuldade de utilizar esse termo. Como referência, dentre outros estudiosos, opta-se por Hall (2000a e 2000b), que sustenta a existência de deslizamentos da noção de identidade para a de identificações.

A princípio, interessa ressaltar que, sem pormenorizar, o termo identidade é utilizado, dentre outras coisas, para remeter a algo uno, acabado, coerente, coeso, linear, integral, único, original e estável. Trata-se de uma concepção Iluminista; procura assimilar a identidade como algo indestrutível - está pronta e não se dissipa. Esse parece ser o ângulo empregado na cotidianidade dos indivíduos comuns: em seus compromissos diários. Os sujeitos constroem representações de si mesmos (estórias), procurando dar sentido de linearidade ao seu ser/existir. Assim, voltam-se a sentir/experimentar a consciência de si mesmos como identidade invariante e, portanto, respeitáveis à luz dos padrões socioculturais, pois que essa tendência à estabilidade permite uma certa previsibilidade de pensamentos e comportamentos. Aos poucos, teóricoepistemologicamente, a noção de identidade-completude sofre deslizamentos e começa a ser pensada como resultante de processos de interação entre sujeitos e sociedade. Apesar disso, ainda se acreditava que a identidade, como resultado, seria algo da qualidade do único e unificado, portando diferente de qualquer outra. Essa percepção ainda é muito comum.

Num cenário mais complexo, deve-se atentar para a fundamental alteração na concepção de identidade ressaltada por Hall ao afirmar que "o sujeito, previamente vivido como tendo uma identidade unificada e estável, está se tornando fragmentado ${ }^{1}$; composto não de uma única, mas de várias identidades, algumas vezes contraditórias ou não-resolvidas” (HALL, 2000a, p. 12). Essa assertiva presentifica uma ruptura definitiva com a possibilidade de a identidade ser essencial, fixa, coesa, permanente, imaculada, mesmo que os indivíduos, pautados pelo senso comum, ainda se autoreferenciem/reconheçam como únicos e inalteráveis.

Sendo assim, sob a perspectiva da complexidade, pode-se dizer que nos diversos momentos e lugares, os sujeitos realizam diferentes identificações, inclusive, opostas, 
contraditórias e/ou incoerentes. As identificações podem, então, ser deslocadas/projetadas em múltiplas direções.

Ainda Hall (2000a) afirma que melhor do que se falar em identidade é falar em identificações (processos). O autor destaca que a sensação de que se possui uma identidade unificada, desde o nascimento até a morte, é devida ao fato de os sujeitos construírem estórias cômodas e coerentes sobre si - representações simbólicas. Procedendo assim, os sujeitos tendem a suturar os fragmentos, as descontinuidades, os deslocamentos e a articula-los como componentes de uma única e grande narrativa sobre o "eu".

Essencialmente, é nas/em relações - dialógicas dialéticas e recursivas - estabelecidas com sua alteridade, que a identidade (re) constrói-se. Assim, à medida que "os sistemas de significação e representação cultural se multiplicam, somos confrontados por uma multiplicidade desconcertante e cambiante de identidades possíveis, com cada uma das quais poderíamos nos identificar - ao menos temporariamente" (HALL, 2000a, p.13).

Disso, pode-se inferir que a noção de identidade guarda estreita relação com a de possibilidade que, por sua vez, de modo geral, somente se dá a conhecer quando da sua materialização nas tensões relacionais.

Nessa acepção, volta-se a afirmar que, em nível teórico-epistêmico, identidade e alteridade não podem ser pensadas como simples lugares assépticos, de exclusão. Isso seria recuperar ideias simplificacionistas que já tiveram seu lugar. $\mathrm{O}$ fato de a identidade e a alteridade serem construções - processos construtivos - articuladas e dependentes à/dá ideia de diferenciação, não as exime de, nos processos inter-relacionais/interacionais, dialógica e recursivamente, realizarem máculas mútuas. Parece que, sob um prisma de mais complexidade, com base nas noções de sistemas abertos e de comunicação como "processo de construção e disputa de sentidos4 "(BALDISERA, 2004), ao entrar em relação, as forças tensionadas tendem a sofrer algum tipo de transformação, independentedente da intensidade.

\section{METODOLOGIA PARA ANÁLISE DA TRANSIÇÃO NA IMAGEM DO BRASIL}

A pesquisa aqui proposta tem um carácter descritivo e histórico-cultural segundo uma lógica hipotético-dedutiva, com aplicação de técnicas de análise documental, de conteúdo e do discurso, às quais corresponde, portanto, uma abordagem mista quantitativa e qualitativa.

\footnotetext{
${ }^{4}$ Noção de comunicação apresentada em Baldissera, 2000 (p. 18-25) e complexificada em Baldissera, 2004 (p. 128-35).
} 
A pesquisa incide sobre o discurso da imprensa portuguesa a respeito do Brasil publicada entre 1834 e 1922. Ao invés de recolher dados de toda a imprensa portuguesa publicada nesse período, foram selecionadas para o estudo, como amostra arbitrária, apenas as revistas ilustradas portuguesas publicadas nesse período dentre as quais aquelas que abordaram os temas que foram identificados e classificados contidos nas matérias pelo viés do estudo da narrativa. Para realizar a análise, foram separados os conteúdos das matérias conforme os títulos selecionados e categorizados de acordo com o assunto, classificados dentro dos seguintes temas: a) Brasil etnográfico; b) Brasil geográfico e natureza; c) Brasil produtivo; personalidades do Brasil e história do Brasil. A primeira classificação está ligada aos dados que trazem as imagens tratadas nas matérias sobre a etnografia brasileira da época, sendo assim definida: população, caráter, usos/costumes e cultura. A segunda, relacionada ao Brasil etnográfico e natureza: navegação, portos e monumentos; A terceira classificação trata dos dados sobre o Brasil produtivo (minas, agricultura e pesca); a quarta classificação personalidades do Brasil, por sua vez, dá-se pela análise dos itens: políticos, literatos e artistas. Enquanto que a quinta classificação trata da história do Brasil que analisa os itens: comemorações cívicas, progresso do Brasil, povoação e expedição. A pesquisa apresenta os dados analisados de acordo com as décadas do período, num total de nove correspondente ao período de 1834 a 1922.

A pesquisa se auxiliou do inventário das revistas ilustradas portuguesas elaborado por Jorge Pedro Sousa (2017b), que já tem em conta as revistas acessíveis em arquivos e bibliotecas públicas portuguesas. Assim sendo, foram estudadas as revistas de periodicidade semanal, quinzenal ou mensal sendo selecionadas as que trazem matérias sobre o Brasil nos assuntos acima informados.

Na primeira parte da pesquisa foi efetuada a localização, inventariação e recolha das matérias sobre o Brasil/ brasileiros publicadas nas revistas selecionadas, entendidas como fontes de informação documentais (análise documental).

Seguidamente, procedeu-se à realização de uma análise quantitativa de conteúdo às matérias localizadas, para percepção global dos temas abordados por termos indexados, com a finalidade de identificar "os pontos substantivos" do discurso e de classificá-los por categorias, criadas a priori sem prejuízo de um ajuste posterior (SOUSA, 2006: 345). Seguiu-se a proposta operativa de Wimmer e Dominick (1996, pp. 174-191), que estipula os seguintes passos para a realização de uma análise quantitativa do conteúdo da mídia: Definição do universo de análise (considerado o recorte temporal 1834-1922); Seleção do universo amostral (revistas ilustradas portuguesas publicadas entre 1834 e 1922, com foco nos temas relevantes sobre o Brasil) que 
mais aparecem nas revistas; Seleção da unidade de análise (matérias com referências ao Brasil e/ou brasileiros); Definição das categorias de análise, anteriormente citadas.

Trabalhou-se com as seguintes categorias: Tipologia da matéria, em função da intencionalidade: informativo-explicativo e interpretativo-opinativo; Tipologia formal da matéria: matéria só constituída por texto escrito; Temas das matérias selecionados: geografia, etnografia e natureza; produtivo, personalidades do Brasil e história do Brasil. Estabeleceu-se um sistema de quantificação (as matérias foram quantificadas conforme décadas dentro do recorte temporal definido) e categorização do conteúdo (as matérias foram contabilizadas nas categorias criadas).

\section{ANÁLISE, DISCUSSÃO E INTERPRETAÇÃO DOS RESULTADOS}

Após traduzidos os dados da análise de conteúdo em gráficos diacrônicos (evolução ao longo do tempo), sincrônicos (cada momento histórico) e totais, identificou-se a atenção dada ao Brasil ao longo desse período (1834-1922).

Na segunda parte da pesquisa foi estudado qualitativamente o discurso produzido sobre o Brasil e/ou brasileiros nas revistas que constituíram o universo amostral. Foi considerado, conforme Eduardo Meditsch (2008), que o jornalismo produz uma forma específica de conhecimento sobre singularidades reais que, não sendo científica, igualmente se afasta do senso-comum. Foi trabalhado, essencialmente, baseado no conceito teórico de imagens correspondendo às projeções do discurso que é apresentado sobre a mente de quem o apreende e às possíveis e consequentes construções mentais de significados para as singularidades reais representadas nestes discursos midiáticos, que correspondem à formação de um imaginário (SOUSA, 2017b: 30). Seguiu-se, neste ponto, a ideia de Gilbert Durand (2002), segundo a qual o imaginário, entendido como o acervo simbólico de imagens disponíveis sobre a realidade, tem uma componente racional e outra não racional, fundada, esta, na imaginação, na fantasia, no mito, enfim, na subjetividade. O mito salienta o autor, é "um sistema dinâmico de símbolos, arquétipos e esquemas (...) [que] tende a compor-se em narrativa" (DURAND, 2002, pp. 6263).

\section{MÉTODOS, ANÁLISES E RESULTADOS}

Foi aplicada neste texto, uma análise de conteúdo sugerida por Motta (2005) com base no estudo da narrativa, onde são elencadas as fontes de informação (matérias) das revistas 
ilustradas portuguesas. Estas foram escolhidas para análise tendo em vista que, segundo Sousa (2017b, p.22) fazia parte de "um tipo de imprensa que penetrava transversalmente toda a sociedade portuguesa alfabetizada de então: a imprensa literária, domínio avassalador na difusão massiva de imagens sobre realidade”. Sendo assim estas as mais bem sucedidas, que, conforme esse autor (...) “exerceram um domínio avassalador na difusão massiva de imagens sobre a realidade".

Segundo Tengarrinha (2013), a imprensa era considerada à época como o principal agente de sustentação dos movimentos de opinião pública que brotavam, essencialmente, entre a minoria de indivíduos alfabetizados e politizados.

O processo narrativo pode ser notado em diversos produtos da linguagem, já que "as narrativas são construções discursivas sobre a realidade humana" (MOTTA, 2005, p. 18). No campo do jornalismo, elas estão presentes nas representações dos acontecimentos sociais que, por sua vez, carregam conflitos, reviravoltas, rupturas, ou seja, o suceder de ações que implicam na transição de um estado para o outro. Para Motta (2005, p.5), "narrar é uma experiência enraizada na existência humana [...] nossas vidas são acontecimentos narrativos, o acontecer humano é uma sucessão temporal e causal”.

A seguir com Motta, "estudar as narrativas como representações sociais pode ensinar muito sobre as maneiras através das quais os homens constroem essas representações do mundo material e social". Segundo esse autor, grande parte dessas representações mentais se estrutura na forma de narrativas, "tanto nos relatos pessoais [...] quanto na história universal ou nas histórias de povos ou nações" (MOTTA, 2012, p. 29). Nesse contexto, enquadra-se a história do Brasil, objeto desse estudo.

À época, conforme narrativas, o Brasil despontava com suas riquezas naturais a chamar a atenção do mundo inteiro, um acontecimento inusitado, o descobrimento de um novo país, a formação de uma população, um acontecimento temporal marcante na história tanto do país como do mundo.

Para fazer a análise, foram separadas as matérias por temas afins, categorizadas de acordo com a identificação, a classificação e a característica da informação atribuída à fonte, assim como a intensidade e a frequência com que o assunto surge nas revistas.

Em última análise, esses dados incluem os temas subdivididos conforme classificação: Geografia - cidades, navegação, portos, monumentos; Etnografia e natureza - população, caráter, usos e costumes, língua, raças, religião; Brasil produtivo - minas, agricultura e pesca; História do Brasil - Povoação, expulsão, invasão, expedição; Personalidades brasileiras: políticos, datas cívicas, escritores, artistas e esportistas; economia e relações internacionais; 
peças literárias (poesia e prosa literária da autoria de brasileiros publicada nas revistas ilustradas portuguesas).

Na sequência, comentam-se as matérias de cada tema específico conforme posição na classificação final. A análise dos dados está representada posteriormente por meio de quadro, tabela e gráfico, a amostra corresponde à frequência conforme surgimento por década:

O tema personalidades do Brasil, ficou classificado em primeiro lugar, por ter sido o mais citado com duzentas e dez matérias publicadas e distribuídas entre comemorações sobre o descobrimento, comemorações de datas cívicas, tendo sido a década de 1904 a 1913 a que teve mais matérias publicadas;

A temática Geografia do Brasil com matérias destacadas sobre monumentos, paisagens, navegação, cidades e viagens, foi o segundo tema com mais aparição sobre o Brasil num total de cento e dezenove citações sendo que a década que mais aparece é a de 1884 a 1893 com 44 matérias na maioria sobre paisagens;

Em terceiro lugar, surgiu o tema História do Brasil com noventa e duas matérias sobre os seguintes itens: expulsão, invasão, povoação, expedição e comemorações cívicas, sendo que a década de 1884 a 1893 foi a que apresentou mais com 39 matérias sobre os itens comemorações cívicas e progresso do Brasil;

Em quarto lugar, o tema "Etnografia e Natureza" traz matérias publicadas sobre a população, o caráter, usos e costumes, a língua, as raças e a religião, foi o quarto tema de destaque no geral num total de trinta e seis matérias sendo que a década que mais aparece é a de 1904 a 1913 com vinte e sete matérias, com destaque para raças;

E por último, em quinto lugar, ficou o tema Brasil produtivo que destacou matérias sobre minas, agricultura e pesca, num total de vinte e duas matérias, sendo que a década que mais aparecem matérias é a de 1834 a 1843 com destaque para os itens comércio e indústria no Brasil.

A seguir, representações traduzidas por meio de Quadro 1, Tabela 1 e Gráfico1. 
Quadro 1 - Análise de conteúdo

\begin{tabular}{|c|c|c|}
\hline Temas & $\begin{array}{c}\mathrm{N}^{0} \text { de } \\
\text { matérias }\end{array}$ & $\%$ \\
\hline $\begin{array}{l}\text { Personalidades do Brasil (políticos, datas cívicas, escritores, artistas e esportistas); } \\
\text { economia e relações internacionais; peças literárias (poesia e prosa literária da autoria de } \\
\text { brasileiros). }\end{array}$ & 210 & 36,8 \\
\hline Brasil geográfico (navegação, portos e monumentos) & 159 & 27,9 \\
\hline História do Brasil (comemorações cívicas, progresso, povoação e expedição). & 152 & 26,7 \\
\hline Brasil etnográfico e natureza (população, caráter, usos/costumes e cultura). & 27 & 4,7 \\
\hline Brasil Produtivo (minas, agricultura e pesca). & 22 & 3,9 \\
\hline Total & 540 & 100 \\
\hline
\end{tabular}

Fonte: a autora (2019)

Tabela $1-\mathrm{N}^{\mathrm{o}}$ de matérias de temas por década

\begin{tabular}{|c|c|c|c|c|c|c|c|c|c|c|}
\hline $\begin{array}{l}\text { Década/ } \\
\text { Tema }\end{array}$ & $\begin{array}{l}1834 / \\
1843\end{array}$ & $\begin{array}{l}1844 / \\
1853\end{array}$ & $\begin{array}{l}1854 / \\
1863\end{array}$ & $\begin{array}{l}1864 / \\
1873\end{array}$ & $\begin{array}{l}1874 / \\
1883\end{array}$ & $\begin{array}{l}1884 / \\
1893\end{array}$ & $\begin{array}{l}1894 / \\
1903\end{array}$ & $\begin{array}{l}1904 / \\
1913\end{array}$ & $\begin{array}{l}\text { 1914/ } \\
1922\end{array}$ & Total \\
\hline Personalidades & 1 & 2 & 3 & 3 & 32 & 52 & 24 & 51 & 42 & 210 \\
\hline Geográfico & 12 & 7 & 17 & 1 & 28 & 44 & 12 & 27 & 11 & 159 \\
\hline História & 18 & 0 & 7 & 0 & 10 & 39 & 20 & 34 & 24 & 152 \\
\hline Etnográfico & 2 & 1 & 1 & 4 & 3 & 5 & 1 & 7 & 3 & 27 \\
\hline Produtivo & 5 & 4 & 0 & 2 & 0 & 3 & 1 & 3 & 4 & 22 \\
\hline Total no período & 38 & 14 & 28 & 10 & 73 & 143 & 58 & 122 & 84 & 570 \\
\hline$\%$ & 6,7 & 2,5 & 4,9 & 1,8 & 12,8 & 25,1 & 10,2 & 21,4 & 14,7 & 100 \\
\hline
\end{tabular}

Fonte: a autora (2019) 
Gráfico 1 - Número de matérias de temas

\section{Número de matérias por temas}

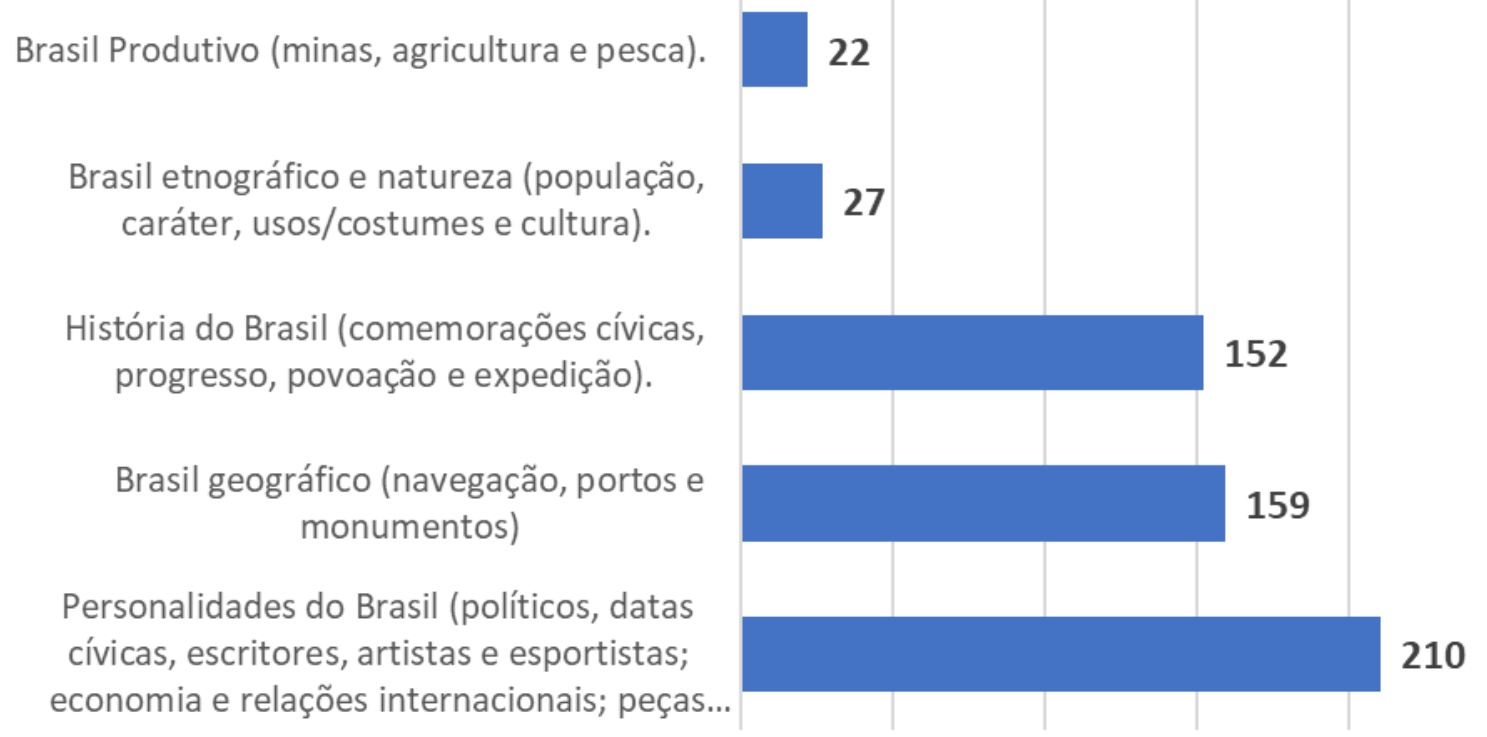

Fonte: a autora (2019)

\section{CONSIDERAÇÕES FINAIS}

Este texto, que teve como objetivo o de analisar alguns aspectos sobre o Brasil, a partir das matérias publicadas sobre os assuntos distintos - Geografia, Etnografia, Produtivo, Personalidades e História do Brasil em determinado recorte temporal (1834-1922), conseguiuse assim evidenciar as imagens de destaque dadas ao Brasil no período pesquisado. Ao propor diferenciações estabelecidas, a partir da teoria da narrativa, foi possível detectar que as duas décadas (1884 a 1893) e (1904/1913) tiveram destaque especial para os temas Personalidades e História do Brasil, dentre os publicados com mais frequência - Personalidades e Historia do Brasil.

Sobre análise da narrativa jornalística, Motta afirma que, ao fazê-las, “estamos buscando compreender o jornalismo como uma atividade produtora de sentidos, formadora e estruturadora do pensamento contemporâneo em todas as dimensões que esta afirmação sugere" (MOTTA, 2005, p. 23). Acredita-se que as revistas ilustradas portuguesas tenham exercido tal função comunicativa, ou seja, a de mostrar para o mundo um novo país.

Ao analisar as matérias sobre o Brasil Produtivo e Brasil Etnográfico, conforme se evidencia pelos números, menos citadas. $\mathrm{O}$ destaque median para temas relacionados às Personalidades do Brasil e para o Brasil Etnográfico que revela a importância para a época o 
nascimento de desenvolvimento de uma nova nação e para a etnografia, enquanto que o tema História do Brasil, é majoritário, visto que destacavam em amplitude os fatos, os acontecimentos, entre outros.

Foi possível observar em todas as matérias encontradas sobre o Brasil, que era dada muita atenção ao país por tratar-se de um país do novo mundo, com muito potencial a tornar-se uma grande potência.

A ênfase nos temas Personalidades do Brasil e Geografia, nas décadas 1894 a 1893 e a de 1904 a 1913 foram o enfoque escolhido para destacar posições de políticos, artista e esta posição do autor ou autores do texto evidencia o objetivo de mostrar esses assuntos no progresso do Brasil. Matérias que destacaram o quanto o Brasil tinha potencial a ser desenvolvido e para tornar-se uma potencia do futuro. 


\section{REFERENCIAS}

BALDISSERA, R. Imagem-conceito, a indomável orgia dos significados. In: Anais do XXVI Congresso Brasileiro de Ciências da Comunicação. São Paulo: Intercom, 2003. CD-ROM.

DONDIS, Donis A.Sintaxe da linguagem visual. São Paulo: Martins Fontes, 2007.

DURAND, G. Estruturas antropológicas do imaginário. 3. ${ }^{a}$ edição. São Paulo: Martins Fontes, 2002.

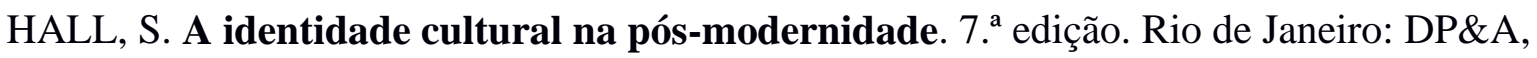
2002.

JOLY, M. Introdução à análise da imagem. Campinas, Papirus, 1996.

MEDITSCH, E. O jornalismo como uma forma de conhecimento? Uma abordagem qualitativa. In: Sousa, J. P. (org.). Jornalismo: História, Teoria e Metodologia da Pesquisa. Porto: Edições Universidade Fernando Pessoa, 2008, pp. 7-12.

MOTTA, L. G. Análise crítica da narrativa, Editora UnB, Brasília, 2012.

MOTTA, Luiz Gonzaga. Narratologia - teoria e análise da narrativa jornalística. Brasília, Casa das Musas, 2005.

SCHAFER, M. B.; FLORES, D. A digitalização de documentos arquivísticos no contexto brasileiro. Tendências da Pesquisa Brasileira. Ciência da Informação, v. 6, n. 2, 2014.

SILVERSTONE, R. Por que estudar a mídia? São Paulo: Loyola, 2002.

SOUSA, J. P. A imprensa portuguesa durante a Monarquia: das origens a 1910. In: SOUSA, J. P.; LIMA, H.; HOHLFELDT, A. e BARBOSA, M., orgs. Uma História da Imprensa Lusófona. Portugal. Porto, Media XXI, 2017a, pp. 13-210.

SOUSA, J. P. Elementos de Teoria e Pesquisa da Comunicação e dos Media. Porto, Edições Universidade Fernando Pessoa, 2006.

TENGARRINHA, J. Nova História da Imprensa Portuguesa Das Origens a 1865. Lisboa, Círculo de Leitores, 2013.

WIMMER, R. D. e DOMINICK, J. R. La Investigación Científica de los Medios de Comunicación. Una Introducción a Sus Métodos. Barcelona: Bosch, 1996. 